\title{
High Cycle Fatigue Behaviour of Functional Spinal Units
}

\author{
Gerd HUBER ${ }^{1 *}$, Daniel M. SKRZYPIEC1, Anke KLEIN², \\ Klaus PÜSCHEL ${ }^{2}$ and Michael M. MORLOCK ${ }^{1}$
}

\author{
${ }^{1}$ Institute of Biomechanics, TUHH Hamburg University of Technology, Denickestrasse 15, 21073 Hamburg, \\ Germany \\ ${ }^{2}$ Department of Legal Medicine, UKE, University Hospital Hamburg, Butenfeld 34, 22529 Hamburg, \\ Germany
}

Received June 4, 2009 and accepted May 6, 2010

\begin{abstract}
Vibrations have been shown to be an important risk factor for spinal pathologies. The underlying mechanisms are poorly understood and in vivo data scarce and difficult to obtain. Consequently numerical models are used to estimate spinal loading; requiring fatigue strength information, which was obtained in this study for spinal specimens from young and old male donors of working age in vitro. Bone mineral density (BMD) and endplate area were determined using CT scans. Three groups were investigated: young specimens in neutral posture, young in flexed posture, and old in neutral posture. The loading consisted of 300,000 sinusoidal compression cycles of $2 \mathrm{kN}$, inducing a nucleus pressure peek of approximately 1.4 MPa. No failure of the young specimens in neutral posture was observed, but four specimens from older donors with low BMD failed. The product between endplate area and $B M D$ was shown to be useful to predict fatigue strength for old donors and should therefore be considered with regard to whole body vibration injuries. In flexed posture, two specimens from young donors failed. One failure can be attributed to low $B M D$ following the trend for the old specimens; the other failure could not be explained, leaving the influence of flexion yet unclear.
\end{abstract}

Key words: Lumbar spine, in vitro, Fatigue, Flexion, Prevention, Vibration

\section{Introduction}

Vibrations and impact loads are potential risk factors for spinal failure. In particular, the combination of long exposure durations and constrained sitting postures might accelerate disc degeneration or endplate failure ${ }^{1-3)}$. Vertical vibrations and impacts, as occurring when working for example with heavy haul trucks, were shown to be potentially harmful ${ }^{4)}$. Large cohorts showed that long term exposure to whole body vibrations due to badly damped seats lead to significantly decreased disc heights ${ }^{5}$. The associated risks are addressed by regulations and recommendations aiming to limiting the permitted exposure to vibration (e.g. 2002/44/EG; ISO 2631-1, 1997; ISO 2631-5, 2004). Beside the personal burden, the economic cost of low back injuries is immense; exceeding those caused by cardiovascular diseases, cancer and AIDS combined ${ }^{6)}$. For dorsopathy, excluding fractures and osteoporosis, 8.4 billion euro was spent in Germany alone in the year 2002, not taking into account the lost working time ${ }^{7)}$. For compulsorily insured workers, about 3 working days are lost per year ${ }^{8)}$.

The mechanisms and pathways by which external vibrations cause internal damage are not well understood - especially since in vivo studies with healthy subjects are nearly impossi-

*To whom correspondence should be addressed.

E-mail: g.huber@tuhh.de ble. A better understanding of the mechanism involved could improve the appraisal of occupational diseases, enable the determination of duty cycles for implants and also improve the development of prevention systems. Numerical simulations can help in the estimation of spinal loading. Whole body models, validated with in vivo measurements, were used to predict spinal loading for humans exposed to whole body vibration $\left.{ }^{9}, 10\right)$. Regardless the controversy if these kinds of models are already able to predict real behaviour, they are only made to determine loading of substructures. In order to interpret the findings of the models with regard to potential failure of the structure, spinal fatigue strength has to be known additionally.

Fatigue testing of spinal specimens has been rarely performed in vitro. A comprehensive work with 70 specimens of donors that had reached the second half of their working age $(51 \pm 18 \mathrm{yr})$ was done by Brinckmann et $\left.a l^{1}\right)$. In this study, several protocols with peek loads up to $7.1 \mathrm{kN}$ compression were applied. The number of load cycles was limited to 5,000, but already loading below $3 \mathrm{kN}$ leads to failure rates of almost $50 \%$.

Fatigue in vitro measurements with low numbers of cycles till failure $(1,000-10,000$ cycles, $0.33-1 \mathrm{~Hz})$ were reported by other authors as well $1,11,12)$. These low cycle numbers are most likely caused by the high fatigue load used. These types of fatigue measurements with low numbers of cycles and very 
high loading peeks is not in the main focus with regard to health safety in the workplace, but they are indicating influencing factors on fatigue failure, which might be valid for high cycle fatigue failures as well. Lumbar motion segments from middle-aged donors $(49.2 \pm 17.3 \mathrm{yr})$ exhibited higher fatigue life than those of rather old donors $(80.7 \pm 7.8 \mathrm{yr})$ when exposed to different loading regimes with peak compressive forces ranging from $1.3 \mathrm{kN}$ to $3.15 \mathrm{kN}^{11}$ ). This was associated with the superior bone mineral content of the middle-aged specimens. Furthermore, flexion and shear was observed to decrease the fatigue life ${ }^{11)}$. Fatigue loading with peak loads of $2 \mathrm{kN}$ to $4 \mathrm{kN}$ lead to spinal segment failure in less then 1,000 cycles. For the donors, advanced in years $(63.0 \pm 18.2 \mathrm{yr})$, these loads resembled 60 to $80 \%$ of the predicted ultimate compressive strength - calculated based on the bone mineral content ${ }^{12)}$.

In a recent study from the author's group the test design differed fundamentally. The numbers of cycles was clearly increased while the loading was reduced to a more physiological one. Exclusively motion segments from young donors $(\mathrm{n}=30,33 \pm 6 \mathrm{yr})$ were harvested and exposed to 100,000 cycles of loading in the physiological range. Five different loading protocols varying in amplitude and offset were applied. The weakest protocol went from $0 \mathrm{kN}$ to $1 \mathrm{kN}$ and the most harmful protocol went from $0 \mathrm{kN}$ to $2 \mathrm{kN}$. However, it was shown that only two specimens in this age range failed within the enduring loading of 100,000 cycles. The two failed specimens had been assigned to the group with the highest loading exposure $(n=6)$, but they coincidently exhibited pure bone mineral density $(B M D)^{13)}$. Although only few failures could have been provoked the study showed, that the fatigue strength of young donor's specimens exposed to high numbers of loading cycles is high. It appears, that age or mechanically related factors as BMD have to be taken into account. An open question concerns the link of in vitro fatigue test to the in vivo situation of people in the workplace. If the force on the spine caused by whole body vibrations is predicted by e.g. numerical methods, it is not clear if the exposed numbers of cycles to failure are potentially harmful for different individuals.

An attempt can be made by relating the numbers of load cycles to failure $\left(\mathrm{N}_{\mathrm{K}}\right)$ of a specimen exposed to cyclic loading (mean force: $\mathrm{F}_{\text {mean }}$; peak to peak force: $\mathrm{F}_{\mathrm{P} 2 \mathrm{P}}$ ) to its ultimate strength $\left(\mathrm{F}_{\max }\right)$ by using the equation suggested by Seidel et $a l^{14)}$ :

$$
\mathrm{N}_{\mathrm{K}}=\left(\frac{\mathrm{F}_{\max }-\mathrm{F}_{\text {mean }}}{0.5 \cdot \mathrm{F}_{\mathrm{P} 2 \mathrm{P}}}\right)^{6}
$$

In combination with the prediction of the ultimate strength of specimens published by Brinckmann et al ${ }^{15}$.

$$
\mathrm{F}_{\max }=0.32 \mathrm{kN}+0.00308 \cdot \mathrm{BMD} \cdot \mathrm{AREA} \cdot \frac{\mathrm{kN}}{\frac{\mathrm{mg} \mathrm{K}_{2} \mathrm{HPO}_{4}}{\mathrm{ml}} \cdot \mathrm{cm}^{2}}
$$

a simple prediction for the fatigue behaviour would be available. This hypothesised relation only depends on the product of $B M D$ and endplate area (AREA).

The aim of this study was to investigate the high cycle fatigue strength of spinal specimens from male donors of working age. Within this context it was especially analysed how specimen posture and spinal characteristics like age,
BMD and endplate size might be used to predetermine this.

\section{Subjects and Methods}

For the in vitro experiments lumbar functional spinal units (FSU) level L4/L5 from male donors were harvested after consent. The specimens were wrapped in saline-soaked gauze, double sealed in plastic bags and frozen at temperature below $-20^{\circ} \mathrm{C}$ until testing. Computed tomography (CT) scans of both segment's vertebrae were performed in the frozen state. Specimens with pathologic deformities were eliminated prior to the in vitro experiments. A CT-phantom was additionally placed in the image area of the CT scanners (S5VA40A, Siemens, Munich, Germany \& Mx8000 IDT 16, Philips Healthcare, DA Best, The Netherlands). This phantom consisted of three phials filled with an aqueous solution of dipotassium phosphate $\left(\mathrm{K}_{2} \mathrm{HPO}_{4}\right)$ in different concentrations. The absorption of X-rays due to $\mathrm{K}_{2} \mathrm{HPO}_{4}$ is similar to that of the mineral fractions of the bone. The concentrations were 0, 100 and $500 \mathrm{mg} \mathrm{K} \mathrm{HPO}_{4} / \mathrm{ml}$. With this, the Houndsfield Units received by the scanners could be converted to equivalents of dipotassium phosphate concentrations. Differences in scanners settings or x-ray beam hardening due to different amount of absorbing structures did consequently not influence the results. As a representative $B M D$ value the mean was calculated for a defined rectangular volume $(30 \times 30 \times 15$ voxels, Amira 3.0, Avizio 5.0, Mercury Computer Systems, Merignac, France) placed manually at the centre of each vertebral body (Fig. 1). The positioning of the bounding box was performed by two investigators independently to account for subjective variability. If the values differed by more then $10 \%$ the measurements were repeated. If not, the mean value of both investigators was used for further analyses.

To determine AREA, three-dimensional models of the bony structure were created from the CT data (Amira 3.0, Avizio 5.0, Mercury Computer Systems, Merignac, France). Firstly, the soft tissue was separated from the bone by threshold segmentation. Cutting planes were chosen at the inferior side of L4 and the superior side of the L5 vertebra. The cutting plane was oriented with respect to the vertebral body such that a closed contour was formed around the circumference of the endplate (other structures, such as the dorsal process or pedicles were eliminated). The three-dimensional coordinates of these line sets were rotated (Matlab, MathWorks Inc., Natick, MA) to account for the non-planar orientation

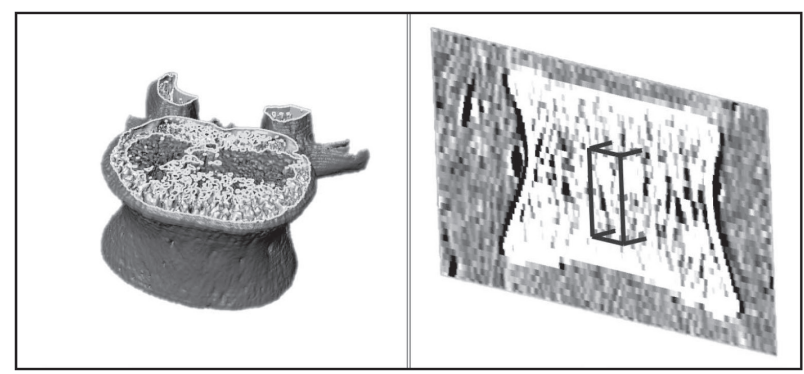

Fig. 1. Endplate area (left) and bone mineral density (right) were determined based on CT data. The plane of the endplate area $(A R E A)$ and the rectangular volume used for $B M D$ calculation is indicated. 
with respect to the CT planes. The area enclosed by the contours (Fig. 1) was determined by piecewise linearization of the kidney shaped cross-sectional area of the endplates (hullfit.m, public domain Matlab function by Peter Wasmeier, p.wasmeier@bv.tum.de). For analysis the mean value of both specimens' vertebral characteristics (AREA, BMD) was used. The VERTEBRAL CAPACITY was calculated as product of $A R E A$ and $B M D$.

The specimens were harvested from younger male adult donors (YOUNG: 20-40 yr) and from donors in the second half of their working age (OLD: 50-60 yr). The former were tested in neutral and flexed posture, the latter only in neutral posture. Thus, three groups with 6 specimens each were investigated: YOUNG NEUTRAL, YOUNG FLEXED and OLD NEUTRAL.

On the day of testing, the spinal muscles were removed, while ligaments (anterior and posterior longitudinal ligaments and the ligamentum flava) were left intact. Care was taken not to damage the disc. The FSUs were potted unconstrained in metal holders using a Polyurethane resin (RenCast FC53, Huntsman, Switzerland). For the neutral posture, the midplane of the segment's disc was potted parallel to the flange of the holders. For the flexed posture, both holders were angled $5^{\circ}$ each in extension during potting, resulting in $10^{\circ}$ flexion after mounting in the hydraulic test machine with its two parallel flanges (Bionix, MTS, MN). The flexion value was chosen based on Andersson et al. who showed that the L4/L5 segment angle changes approximately $10^{\circ}$ during change of posture from standing to unsupported sitting ${ }^{16)}$.

In addition to the hydraulic test machine's axial actuator an additional horizontal actuator was attached to the cross head of the machine to enable force controlled anterior/posterior loading or unrestricted movements in this direction respectively (Fig. 2). The two hydraulic axes were coupled to the moveable flange by means of leaf springs to prevent slip stick or friction within the controller chain. A six degree of freedom load cell (model 30031, Huppert, Herrenberg, Germany) was placed below the specimen. The specimens were immersed in Ringer solution maintained at $37^{\circ} \mathrm{C}$ for testing since the test environment strongly influences the mechanical properties ${ }^{13}$ ). Biological degeneration was minimised by adding Penicillin/ Streptomycin (final concentration: $10 \mathrm{ml} / \mathrm{l}$, PAA Laboratories

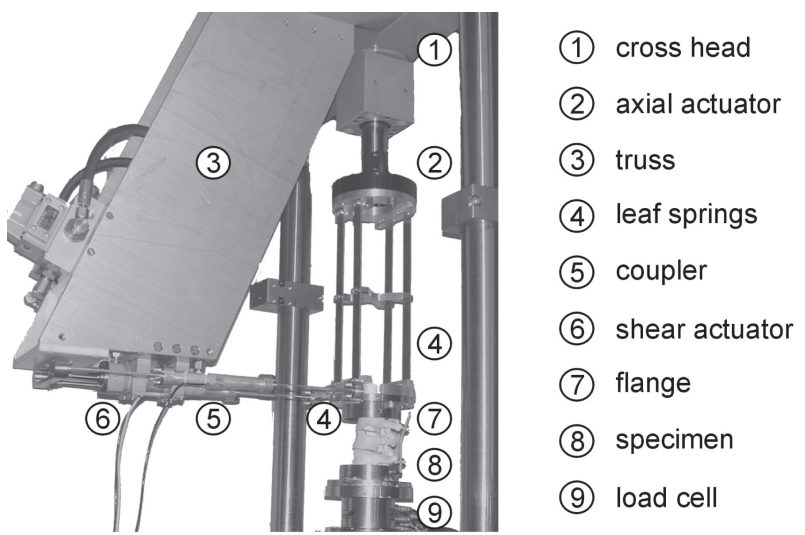

Fig. 2. Modified hydraulic test rig build to enable dynamic loading in axial and anterior-posterior direction.
GmbH, Pasching, Austria).

First the dynamic and quasistatic stiffness of the specimens in the axial and anterior-posterior directions were measured in a non-destructive manner. The maximal axial force was $2 \mathrm{kN}$ and the maximal anterior-posterior force was $0.4 \mathrm{kN}$. These measurements served as pre-conditioning, to diminish the effects of non-uniform starting conditions (such as different swelling status caused by variations in harvesting).

After preconditioning ( $90 \mathrm{~min})$ the segments were exposed to 300,000 cycles of sinusoidal compression $(\sim 18 \mathrm{~h})$. A peak to peak load of $0 \mathrm{kN}$ to $2 \mathrm{kN}$ was applied at a frequency of $5 \mathrm{~Hz}$. The anterior-posterior loading direction was maintained force controlled at $0 \mathrm{kN}$. All other degrees of freedom were restricted. Based on the VERTEBRAL CAPACITY of the harvested specimens and the relations given in equation 1 and 2, almost all specimens were expected to fail with this peek force and this high numbers of cycles. Pilot measurements showed that this loading regime induced nucleus pressures of up to $1.4 \mathrm{MPa}$. This is about the pressure that was measured during lifting $20 \mathrm{~kg}$ in vivo ${ }^{16)}$. Therefore it can be considered as pressures of a high physiological range for repeated loading with a huge number of loading cycles. Specimen height loss was continuously recorded in order to determine cycles to failure based on unsteadiness in the characteristic physiological creep curve.

After mechanical testing, the specimens were deep frozen and then sectioned along the mid-sagittal plane using a diamond saw (EXAKT 310, EXAKT Apparatebau GmbH, Norderstedt, Germany). Photographs of the unloaded sectioned segments were taken and morphologically graded according to the scheme of Thompson et al. ${ }^{18)}$ (Table 1).

Variance analyses to examine the differences between the characteristics of the specimens were accomplished for the three groups. Linear regression analyses were performed for failed specimens. The independent variables were the age or the VERTEBRAL CAPACITY and the dependent variables were linear or logarithmically scaled numbers of cycles to failure. Type II error level for all statistical analyses was chosen to be $\alpha=0.05$.

\section{Results}

The characteristics of the specimens in each group show a wide variation (Table 2). The standard deviations ranged from 10 to $25 \%$ of the corresponding mean values. The mean $B M D$ values between the OLD NEUTRAL and YOUNG FLEXED groups were significantly different $(\mathrm{p}=0.041)$, but the mean endplate areas between groups were not significantly different. A significant decrease of BMD with donor's age was observed for the specimens $\left(\mathrm{r}^{2}=0.38 ; p=0.007\right)$.

The indication of the numbers of load cycles till fatigue failures of specimens based on the creep curve was successful. In most cases the discontinuity in the creep behaviour was quite distinct (Fig. 3). None of the YOUNG NEUTRAL specimens failed during the test period, whereas four of the $O L D$ NEUTRAL specimens with the lowest BMD failed (Table 3). Two of the YOUNG FLEXED group also showed unsteadiness in the characteristic creep curve used to indicate fatigue failure (Table 3). However, for one of them (\#3) this was not very distinct. 
Table 1. Description of the morphologic grade according to Thompson et $\mathrm{al}^{18)}$

\begin{tabular}{ccccc}
\hline Grade & Nucleus & Annulus & End-plate & Vertebral body \\
\hline I & Bulging gel & Discrete fibrous lamellas & Hyaline, uniformly thick & Margins rounded \\
\hline II & $\begin{array}{c}\text { White fibrous tissue } \\
\text { peripherally }\end{array}$ & $\begin{array}{c}\text { Mucinous material } \\
\text { between lamellas }\end{array}$ & Thickness irregular & Margins pointed \\
\hline III & Consolidated fibrous tissue & $\begin{array}{c}\text { Extensive mucinous infil- } \\
\text { tration; loss of annular- } \\
\text { nucleus demarcation }\end{array}$ & Focal defects in cartilage & $\begin{array}{c}\text { Early chondrophytes or oste- } \\
\text { phytes at margins }\end{array}$ \\
\hline IV & $\begin{array}{c}\text { Horizontal clefts parallel to } \\
\text { end-plate }\end{array}$ & Focal disruptions & $\begin{array}{c}\text { Fibrocartilage extending } \\
\text { from subchondral bone; } \\
\text { irregularity and focal scle- } \\
\text { rosis in subchondral bone }\end{array}$ & Ostephytes less than 2 mm \\
\hline V & Clefts extended through nucleus and annulus & Diffuse sclerosis & Ostephytes greater than 2 mm \\
\hline
\end{tabular}

Table 2. Group characteristics $(n=6$ per group, mean \pm SD)

\begin{tabular}{llccc}
\hline & & OLD NEUTRAL & YOUNG FLEXED & YOUNG NEUTRAL \\
\hline age & {$[\mathrm{yr}]$} & $53.5 \pm 3.8$ & $30.5 \pm 8.3$ & $29.0 \pm 7.1$ \\
$B M D$ & {$\left[\mathrm{mg} \mathrm{K}_{2} \mathrm{HPO}_{4} / \mathrm{ml}\right]$} & $117.0 \pm 28.8$ & $161.8 \pm 29.2$ & $152.8 \pm 15.4$ \\
AREA & {$\left[\mathrm{cm}^{2}\right]$} & $17.8 \pm 3.1$ & $16.7 \pm 3.7$ & $15.6 \pm 2.1$ \\
\hline
\end{tabular}

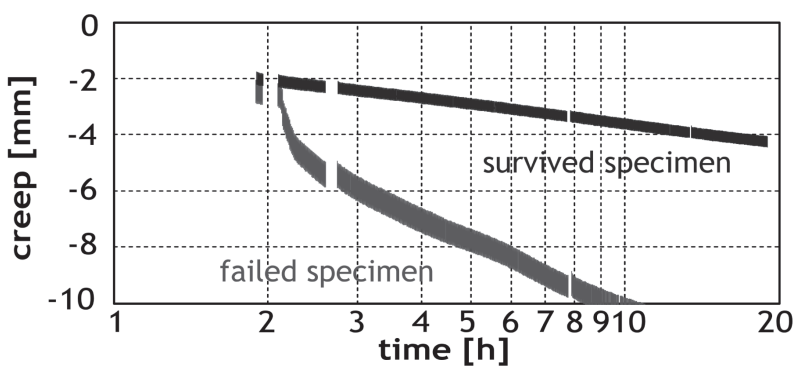

Fig. 3. Examples for the creep curves of a failed and a survived specimen.

The failures that could be detected afterwards were observed exclusively within the vertebral body. This was seen by comparing the pre-testing $\mathrm{x}$-ray image to the post testing section plane (Fig. 4). The Thompson grading based on this section planes exhibited a distinct difference of degeneration grades (Table 4). The YOUNG NEUTRAL specimens appear to be unaffected from the 300,000 load cycles. The mean degeneration grade of these specimens was $1.9 \pm 0.4$ while those of OLD NEUTRAL were clearly higher $(3.6 \pm 0.7)$. YOUNG FLEXED mean Thompson grading was $2.9 \pm 1.3$.

Age alone was not a good predictor of failure. Two specimens of the OLD NEUTRAL group (aged 52 and $50 \mathrm{yr}$ ) did not fail during the 300,000 load cycles (Fig. 5), which can be explained considering the VERTEBRAL CAPACITY (Fig. 6). The two specimens that survived the fatigue testing had $B M D$ values that exceeded those of the others in the group by $50 \%$ and $67 \%$, respectively and for AREA the mean was exceeded by $47 \%$ and $7 \%$, respectively. The hypothesised failure load based on the VERTEBRAL CAPACITY is conservative in most of the cases but not for specimens from older donors with low $B M D$. Regression analyses were only performed based on the data of the four failed specimens in OLD NEUTRAL.
The coefficient of determination between the VERTEBRAL CAPACITY and the logarithmical scaled numbers of cycles was higher (adjusted $r^{2}=0.75, p=0.088$ ) than for the interrelation between age and the numbers of cycles to failure (adjusted $\left.\mathrm{r}^{2}=0.62, p=0.153\right)$. Neither for age nor for VERTEBRAL $C A P A C I T Y$ it was possible to detect significant relations; probably due to the small numbers of failed specimens.

\section{Discussion}

The resistance of young donors' specimens, tested in neutral posture, against cyclic fatigue loading was unexpectedly high. The hypothesised acceptable numbers of cycles were clearly exceeded by most of those specimens from young donors without failure. Specimens from donors in the second half of working age with low VERTEBRAL CAPACITY failed if exposed to fatigue loading with high numbers of cycles as used in this study. The VERTEBRAL CAPACITY calculated out of $A R E A$ and $B M D$ tend to be more appropriate to predict fatigue strength then age. This agrees with measurements of the ultimate compressive strength ${ }^{15)}$. The initially hypothesised equation underestimates the strength of specimens in most cases.

A linear relationship between logarithmical scaled cycles to failure and the VERTEBRAL CAPACITY appears appropriate. However, this curve can hardly be extrapolated to higher $B M D$ or higher VERTEBRAL CAPACITY, respectively, as it is only supported by four measurements from old donors' specimens.

Based on the post testing morphological Thompson grading it is not possible to distinguish if the higher degeneration grades of the older specimens were caused by the cyclic loading or by age related normal degeneration. For YOUNG NEUTRAL lower degeneration grades were assigned to all components of the spinal segments, meaning that the numbers of cycles applied in this study hardly caused damages. 
Table 3. Spinal characteristics and cycles to failure for the $\mathbf{1 8}$ specimens. The six failed specimens are indicated by the respective number in the column ' $\mathrm{Fx}$ '

\begin{tabular}{|c|c|c|c|c|c|c|}
\hline & Fx & age & $B M D$ & AREA & $B M D * A R E A$ & Cycles \\
\hline & {$[\#]$} & {$[\mathrm{yr}]$} & {$\left[\mathrm{mg} \mathrm{K}_{2} \mathrm{HPO}_{4} / \mathrm{ml}\right]$} & {$\left[\mathrm{cm}^{2}\right]$} & {$\left[\mathrm{cm}^{*} \mathrm{mg} \mathrm{K}_{2} \mathrm{HPO}_{4} / \mathrm{ml}\right]$} & {$[* 1,000]$} \\
\hline \multirow{6}{*}{ 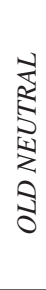 } & $\# 1$ & 48 & 99.9 & 17.2 & 1718.7 & 28.9 \\
\hline & & 50 & 163.5 & 17.5 & 2868.6 & \\
\hline & & 52 & 147.1 & 24.2 & 3554.0 & \\
\hline & $\# 2$ & 56 & 114.7 & 15.1 & 1733.4 & 18.0 \\
\hline & $\# 5$ & 56 & 88.3 & 17.4 & 1539.1 & 1.6 \\
\hline & $\# 6$ & 59 & 88.8 & 15.8 & 1404.7 & 1.8 \\
\hline \multirow{6}{*}{ 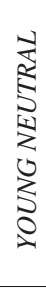 } & & 21 & 163.0 & 18.9 & 3085.8 & \\
\hline & & 22 & 171.2 & 14.1 & 2411.2 & \\
\hline & & 23 & 167.0 & 13.1 & 2184.9 & \\
\hline & & 34 & 138.7 & 15.3 & 2116.8 & \\
\hline & & 36 & 129.1 & 14.1 & 1824.5 & \\
\hline & & 38 & 147.8 & 18.0 & 2663.6 & \\
\hline \multirow{6}{*}{ 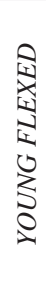 } & $\# 1$ & 20 & 136.4 & 13.6 & 1857.8 & 140.0 \\
\hline & & 21 & 199.5 & 13.3 & 2656.3 & \\
\hline & & 27 & 138.1 & 18.0 & 2491.7 & \\
\hline & & 35 & 148.4 & 23.5 & 3491.7 & \\
\hline & $\# \mathbf{3}$ & 39 & 205.8 & 14.0 & 2887.8 & 215.6 \\
\hline & & 41 & 142.8 & 18.0 & 2569.9 & \\
\hline
\end{tabular}

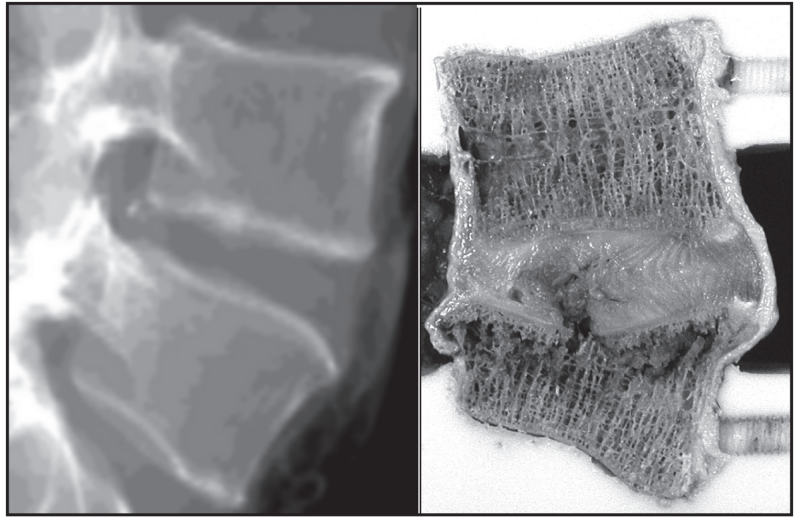

Fig. 4. Pre-testing $x$-ray image (left) and post-testing section (right) of a failed specimen from the OLD NEUTRAL group (\#5) is shown. The middle part of the $\mathrm{L5}$ endplate, which was initially well shaped, failed during loading and the disc tissue was heavily damaged.

Two of the young specimens in the flexed posture failed. One of those (\#1) with low VERTEBRAL CAPACITY fits into the relationship derived for the older specimens whereas the second (\#3) did not. For the former it is therefore not possible to state additional damaging effects due to flexion. The failure can solely be explained by the VERTEBRAL CAPACITY. For the latter it is doubtful if the small unsteadiness in the characteristic creep curve really exhibited a fatigue failure. Only for this single specimen the detection of unsteadiness in the creep curve was doubtful. Morphological investigations after the testing did not exhibit any disruption of the spinal structures. Therefore, it is likely that in this case the identification of fatigue failure based on the creep curve was not meaningful. Consequently the influence of flexion still remains unclear.

The observed exclusive failure within the vertebral body was in good agreement with other in vitro studies, in which high loads, resulting in considerably less cycles to failure, were applied $\left.{ }^{11}, 12,19\right)$. Adams et al. ${ }^{20)}$ observed disc failure in few cases, but this was an effect of combined high loads and close to limit flexion angles, clearly exceeding the $10^{\circ}$ used in this study. The results are inconsistent with the findings presented by Kumar ${ }^{3}$ ) who announced disc failure rather than failure of the bony structures and also contradicts the findings of an in vivo cross sectional study of highly exposed cohorts $^{21)}$. In that study it was shown, that high load exposure influenced the disc height rather than the vertebral bodies. Two issues might be responsible for this. First, the morphological disc grading of the Thompson classification is done with photographs of the section view of unloaded specimens. Clefts in the disc tissue may be not revealed in this method of investigation. Second, the in vitro test design does not account for bone healing during rest between the periods of vibration exposure. It might be possible, that the damage accumulation of the vertebrae is masked by the remodelling while that of the disc is progressing. The former will imply, that failure of the spinal structure occurred earlier than shown in this study, while the later will suppose, that the fatigue strength in vivo is even higher. 
Table 4. Received Thompson grading scores for the specimens after testing

\begin{tabular}{|c|c|c|c|c|c|c|c|c|}
\hline & Fx & age & & mean 1 & al grade & & & \\
\hline & & [yr] & nucleus & annulus & endplate & vertebrae & $\max$ & overall \\
\hline \multirow{6}{*}{ 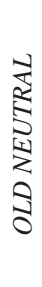 } & $\# 1$ & 48 & 4.5 & 4.0 & 3.0 & 3.5 & 4.5 & 3.8 \\
\hline & & 50 & 2.5 & 2.5 & 3.0 & 3.5 & 3.5 & 2.9 \\
\hline & & 52 & 2.5 & 2.5 & 3.0 & 3.0 & 3.0 & 2.8 \\
\hline & $\# 2$ & 56 & 4.0 & 3.5 & 4.0 & 3.0 & 4.0 & 3.7 \\
\hline & $\# 5$ & 56 & 4.5 & 4.5 & 4.5 & 4.5 & 4.5 & 4.5 \\
\hline & \#6 & 59 & 4.0 & 4.0 & 4.5 & 3.5 & 4.5 & 4.1 \\
\hline \multirow{6}{*}{ 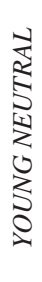 } & & 21 & 1.5 & 1.5 & 3.5 & 1.0 & 3.5 & 1.9 \\
\hline & & 22 & 1.5 & 1.5 & 2.0 & 1.0 & 2.0 & 1.6 \\
\hline & & 23 & 1.0 & 1.5 & 2.0 & 2.0 & 2.5 & 1.7 \\
\hline & & 34 & 1.5 & 1.5 & 3.0 & 1.0 & 3.0 & 1.8 \\
\hline & & 36 & 2.0 & 2.0 & 3.5 & 2.5 & 3.5 & 2.6 \\
\hline & & 38 & 2.0 & 2.0 & 2.0 & 1.0 & 2.0 & 1.8 \\
\hline \multirow{6}{*}{ 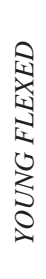 } & $\# 1$ & 20 & 3.5 & 3.5 & 3.0 & 5.0 & 5.0 & 3.8 \\
\hline & & 21 & 1.5 & 1.5 & 2.0 & 1.0 & 2.0 & 1.6 \\
\hline & & 27 & 2.0 & 2.5 & 2.5 & 1.5 & 2.5 & 2.2 \\
\hline & & 35 & 5.0 & 5.0 & 5.0 & 5.0 & 5.0 & 5.0 \\
\hline & $\# 3$ & 39 & 2.0 & 2.0 & 2.0 & 1.0 & 2.0 & 1.8 \\
\hline & & 41 & 2.5 & 3.0 & 2.5 & 3.0 & 3.0 & 2.8 \\
\hline
\end{tabular}

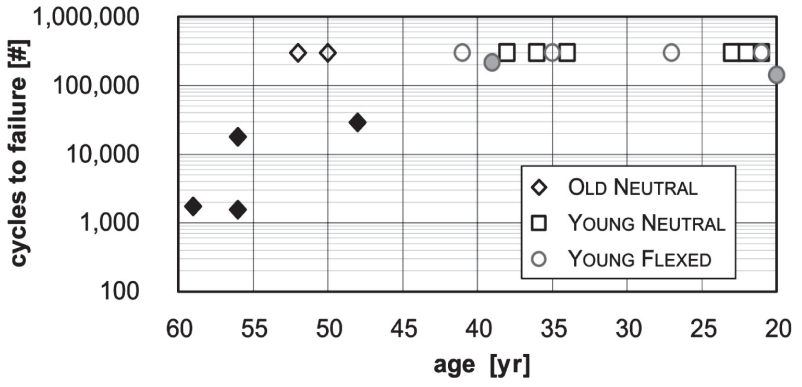

Fig. 5. Fatigue behaviour of the spinal segments versus donor's age. The filled markers represent failed specimens, open markers specimens that survived 300,000 cycles.

\section{Conclusion}

Neither the threefold increase of load cycles compared to the former project of the authors ${ }^{13)}$ nor the inclusion of specimens of older donors and the additional flexion led to the expected high numbers of failure. Only five to six specimens out of 18 failed after exposure to 300,000 cycles of high physiological fatigue loading. From the authors' point of view, further studies with higher numbers to failures, higher loading and different postures are required to deepen the knowledge about fatigue strength especially for young subjects.

It is well understood, that in vitro testing is only an approximation of the in vivo situation. The results can not directly be transferred to the in vivo situation, but trends can be indicated. The influence of artificial load application and constrains as the potting or the reduced degrees of freedom (rotation and lateral translation) could affect the numbers of

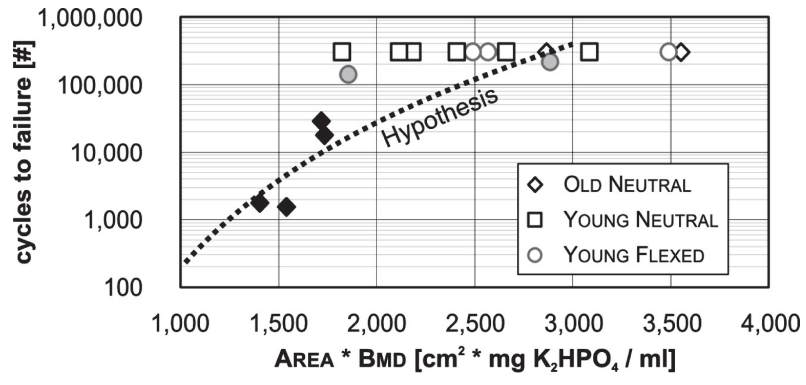

Fig. 6. Fatigue behaviour of the spinal segments against VERTEBRAL CAPACITY. The filled markers represent failed specimens, open markers represents specimens that survived 300,000 cycles.

cycles to failure. However, the transfer to the more complex in vivo situation might be possible using numerical dynamic whole body vibration models.

With regard to fatigue strength and consequently with regard to whole body vibration injuries it has been shown that VERTEBRAL CAPACITY is a crucial factor in predicting spinal compressive fatigue strength.

\section{Acknowledgments}

Institutional support by the German Federal Institute for Occupational Safety and Health (FIOSH) through the Projects F1899 and F2069 was received. The kind support of Dr. Seidel, Dr. Hinz, B. Pöpplau, N. Wilke and A. Matthaei is deeply appreciated. 


\section{References}

1) Adams MA, Hutton WC (1983) The effect of fatigue on the lumbar intervertebral disc. J Bone Joint Surg Br 65-B, 199-203.

2) Brinckmann P, Biggemann M, Hilweg D (1988) Fatigue fracture of human lumbar vertebrae. Clin Biomech 3 (Suppl 1), S1-S23.

3) Kumar S (2001) Theories of musculoskeletal injury causation. Ergonomics 44, 17-47.

4) Kumar S (2004) Vibration in operating heavy haul trucks in overburden mining. Appl Ergon 35, 509-20.

5) Brinckmann P, Frobin W, Biggemann M, Tillotson M, Burton K (1998) Quantification of overload injuries to thoracolumbar vertebrae and disc in persons exposed to heavy physical exertions or vibration at the workplace, Part II, Occurrence and magnitude of overload injury in exposed cohorts. Clin Biomech 13 (Suppl 2), S1-S36.

6) Fordyce WE (1995) Back pain in the workplace, management of disability in nonspecific conditions, IASP Press, Seattle.

7) Statistisches Bundesamt Deutschland (2004) Krankheitskosten 2002 Presseexemplar. Wiesbaden, Bearbeiter: Böhm, Cordes, Forster Krah in Zusammenarbeit mit Mitarbeiterinnen und Mitarbeitern der Gruppe VIII A des Statistischen Bundesamtes (in German).

8) AOK-Bundesverband (2004) Krankheitsartenstatistik 2003. Bonn, Bearbeiter: Ute Jacobs-Spielmanns (in German).

9) Mischke C, Wölfel HP (2007) Einfluss individueller Geometrie auf die Ergebnisse eines numerischen Modells der unteren Lendenwirbelsäule, Humanschwingungen - Auswirkungen auf Gesundheit, Leistung, Komfort, VDI-Berichte 2002, VDI Verlag GmbH, Düsseldorf (in German).

10) Hofmann J, Pankoke S, Wölfel HP (2003) Individualisierbares Finite-Elemente-Modell des sitzenden Menschen zur Berechnung der Beanspruchungen bei Vibrationsanregung in verschiedenen Raumrichtungen und Stoßanregung an einer Reihe von Körperstellen - Ganzkörpermodell und Submodell der unteren Lendenwirbelsäule (Schlußbericht), Bundesanstalt für Arbeitsschutz und Arbeitsmedizin (Fb 994), Wirtschaftsverlag NW/Verlag für neue Wissenschaft $\mathrm{GmbH}$, Berlin (in German).
11) Gallagher S, Marras WS, Litsky AS, Burr D, Landoll J, Matkovic V. (2007) A comparison of fatigue failure responses of old versus middle-aged lumbar motion segments in simulated flexed lifting. Spine 32, 1832-9.

12) Hansson TH, Keller TS, Spengler DM (1987) Mechanical behaviour of the human lumbar spine. II. Fatigue strength during dynamic compressive loading. J Orthop Res 5, 479-87.

13) Huber G, Paetzold H, Püschel K, Morlock MM (2005) Verhalten von Wirbelsäulensegmenten bei dynamischer Belastung, Schriftenreihe der Bundesanstalt für Arbeitsschutz und Arbeitsmedizin, Fb 1062 , Wirtschaftsverlag NW, Berlin (in German).

14) Seidel H, Pöpplau BM, Morlock MM, Püschel K, Huber G (2008) The size of lumbar vertebral endplate areas - prediction by anthropometric characteristics and significance for fatigue failure due to whole-body vibration. Int $\mathrm{J}$ Ind Ergon 38, 844-55.

15) Brinckmann P, Biggemann M, Hilweg D (1989) Prediction of the compressive strength of human lumbar vertebrae. Spine 14, 606-10.

16) Andersson GB, Murphy RW, Ortengren R, Nachemson AL (1979) The influence of backrest inclination and lumbar support on lumbar lordosis. Spine 4, 52-8.

17) Wilke HJ, Neef P, Caimi M, Hoogland T, Claes LE (1999) New in vivo measurements of pressures in the Intervertebral disc in daily life. Spine 24, 755-62.

18) Thompson JP, Pearce RH, Schechter MT, Adams ME, Tsang IKY, Bishop PB (1990) Preliminary evaluation of a scheme for grading the gross morphology of the human intervertebral disc. Spine 15, 411-5.

19) Gallagher S, Marras W, Litsky AS, Burr D (2005) Torso flexion loads on the fatigue failure of human lumbosacral motion segments. Spine 30, 2265-73.

20) Adams MA, Hutton WC (1985) Gradual disc prolapse. Spine 10, 524-30.

21) Brinckmann P, Frobin W, Biggemann M, Tillotson M, Burton K (1998 Quantification of overload injuries to thoracolumbar vertebrae and discs in persons exposed to heavy physical exertions or vibration at the workplace, Part II, Occurrence and magnitude of overload injury in exposed cohorts. Clin Biomech 13 (Suppl 2), S1-S36. 